\title{
O FENÔMENO DE DEUS A PARTIR DA IDEA INFINITATIS EM HUSSERL, SARTRE, LÉVINAS E MARION*
}

\author{
Wojciech Starzynski*
}

\begin{abstract}
RESUMO
O termo "virada teológica da fenomenologia francesa" foi introduzido por D. Janicaud para estigmatizar certa tendência da teologização da fenomenologia. Se retiramos dessa expressão a significação negativa, uma questão mais séria se põe, já não de desqualificar tal ou qual autor, mas aquela de um lugar ou de uma maneira de acontecer essa "virada" na via fenomenológica do pensamento. Pode-se indicar tal momento em que se produz o evento da ocorrência ou de uma revelação de Deus? Pondo à parte a solução metafísica das provas da existência de um ente privilegiado, apresento a hipótese que será o fio condutor deste trabalho: o pensamento filosófico sobre Deus, sua eventual revelação, pode racionalizar-se essencialmente no domínio da filosofia do infinito, e mais precisamente, inspirando-se do pensamento cartesiano, em que a ideia do infinito aparece à subjetividade. Servindo-me deste motivo, gostaria de examinar as variantes de suas interpretações fenomenológicas, seguindo os exemplos-chave de Husserl, Sartre, Lévinas, para enfim pôr em questão a fenomenologia da doação de J.-L. Marion.
\end{abstract}

Palavras-chave: Infinito. Fenomenologia. Husserl. Sartre. Lévinas. Marion.

\section{RÉSUMÉ}

Le terme "tournant théologique de la phénoménologie française » a été introduit par D. Janicaud pour stigmatiser certaine tendance de théologisation de la phénoménologie. Cependant si on enlève de cet expression la signification négative, une question plus serieuse se pose, non plus de disqualifier tel ou tel auteur mais celle d'un lieu ou d'une façon d'advenir ce «tournant» sur la voie phénoménologique de la pensée.

\footnotetext{
* Tradução para o português de Ana Cristina Armond, Fábio Júlio Fernandes, Francisca Maria Oliveira Linhares e Polyana Tidre.

** Pesquisador do Institute of Philosophy and Sociology of the Polish Academic of Sciences. E-mail: wojciech.starzynski@entre.pl
} 
Peut-on indiquer tel moment où se produit l'evenement de l'advenue ou d'une révélation de Dieu ? Mettant à part la solution métaphysique des preuves de l'existence d'un étant privilégié, je pose l'hypothèse qui sera le fil conducteur de mon intervention: la pensée philosophique de Dieu, son éventuel révélation peut se rationaliser essentiellement dans le domaine de la philosophie de l'infini, et plus précisément en s'inspirant de la pensée cartésienne où l'idée de l'infini apparaît à la subjectivité. En me servant de ce motif, je voudrais examiner les variantes de ses interprétations phénoménologiques en suivant les examples-clés de Husserl, Sartre, Lévinas pour enfin mettre en question la phénoménologie de la donation de J.-L. Marion.

Mots-clés: Infini. Phénoménologie. Husserl. Sartre. Lévinas. Marion.

A referência crítica à teologia parece ser fundada na tese de Husserl sobre "a transcendência de Deus posta fora de circuito". O fundador da Fenomenologia precisa, no entanto, que se trata de excluir do problema do fundamento "o sentido de uma causa (Ursache) em termos de uma causalidade de coisa (dinglichkausalen)", ou "de um ser 'divino' exterior ao mundo: basta-nos que esse ser não seja somente transcendente ao mundo, mas manifestamente também à consciência absoluta". Podemos admitir que a tese do caráter absoluto da consciência elimina uma possibilidade do aparecimento de um outro absoluto, mantido nesse caso na esfera transcendental excluída pela redução fenomenológica. Assim esboçada, a questão de Deus encontra sua confirmação na interpretação husserliana da via filosófica de Descartes. Husserl, que se pretende "neo-cartesiano", segue Descartes na etapa da dúvida e até a afirmação do cogito e do princípio de evidência. Quando se trata dos passos seguintes do autor das Meditações e, mais precisamente, de sua "virada" da Meditatio III, onde o ego cede o primado a Deus, Husserl, nas Cinco lições sobre a idéia da Fenomenologia, afirma categoricamente: "se nos lembramos das Meditações III e IV, pensamos nas provas da existência de Deus, nas remissões à veracitas dei e a coisas semelhantes. Todavia, sejamos firmemente céticos ou, antes,

1 HUSSERL, E. Idées directrices pour une phénoménologie. Tradução de Paul Ricoeur. Paris: Gallimard, 1985, p. 191-192. 
críticos"2. Do mesmo modo, nas Meditações cartesianas, quando Husserl busca as "forças vitais" que emanam das Meditationes, ele se concentra no ponto de partida marcado pela dúvida radical, a partir do qual o ego cogito aparece como a subjetividade transcendental, "considerada como base última e apodítica do juízo sobre a qual toda a filosofia radical deve ser fundada" . Em seguida, Husserl repreende em Descartes "a virada fatal" que leva à metafísica da substância e às "deduções segundo o princípio de causalidade" pelo qual ele é responsável do contrassenso do "realismo transcendental"4. Assim, uma possibilidade de retomada fenomenológica das teses da metafísica do finito e do infinito é rejeitada, o que não quer dizer, entretanto, que a questão do infinito não se reduz senão à metafísica. Num de seus esboços da "via cartesiana", Husserl pensa a redução fenomenológica e, mais precisamente, seu componente volitivo consistindo numa decisão radical da mudança de atitude, como uma mudança que implica o abandono do campo do finito e a passagem a uma dimensão do infinito. Esse momento descrito no curso sobre Erste Philosophie suscita uma fascinação ou admiração de Husserl pela abertura do acesso do domínio ilimitado da verdade:

É portanto esse único império universal (Weltreich) do belo (...) ao qual eu próprio pertenço pelas fibras mais íntimas da minha personalidade e que, por sua vez, me pertence como me sendo próprio, como o que me interpelam, de modo inteiramente pessoal, e para o qual tenho vocação (...) E se respondo a esse chamado, que faria de outro senão me perder eu próprio enquanto sou um eu finito (...) para me reencontrar a mim mesmo, reencontrar meu eu autêntico e verdadeiro, meu eu infinito, purificado de toda impureza terrestre $?^{5}$

2 HUSSERL, E. L'idée de la phénoménologie: cinq leçons. Tradução de Alexandre Lowit. Paris: Presses universitaires de France, 2000.

3 HUSSERL, E. Meditações cartesianas. Tradução de M. De Launay. Paris: PUF, 1980, p. 61.

${ }^{4}$ Ibidem, p. 68.

5 HUSSERL, E. Philosophie première. v. 2.Tradução de Arion L. Kelkel. Paris: PUF, 2002, p. 22. 
Ele se põe a questão de onde vem este chamado, que de uma maneira tão profunda e poderosa motiva o filósofo? Segundo Husserl (2002), a situação da vocação em geral e da vocação filosófica, em particular, consiste numa resposta ao chamado: "o verdadeiro filósofo não é verdadeiramente ele mesmo senão à condição de que responda a um chamado, ao chamado que lhe dirige a ele a ideia de uma sapientia universalis e que cobra dele uma dedicação absoluta". Nesse momento, na atitude do engajamento total:

Vivendo assim pressentindo o eterno no temporal, o puro no impuro, o infinito no finito e o realizando como beleza pura no incansável ato de amor, o que obtenho não é somente a "felicidade", mas a felicidade, ou seja, esse puro contentamento que é o único a me proporcionar satisfação ${ }^{6}$.

Sartre, que foi um dos primeiros que divulgou no solo francês as descobertas de Husserl e de Heidegger desde o início de L'être et le néant, introduz "o dualismo do finito e do infinito", que diz respeito, dessa vez, ao fenômeno no sentido kantiano, de uma aparição no seio de uma intuição sensível. Esse gesto de redução indireta de toda a esfera teológica como pertencendo à transcendência ôntica persiste também na referência positiva efetuada por Sartre à prova ontológica cartesiana. Como bem sabemos essa prova, em sua versão original, examinava as propriedades de uma ideia particular, aquela do ens summe perfectum, ou de Deus, cuja existência pertence necessariamente a sua essência. Na versão existencialista, Sartre retoma a estrutura da "prova", que para ele torna-se uma experiência fenomenológica da consciência segundo a qual "o fenômeno de ser é ontológico", o que significa que "ele é um chamado de ser" paradigmática da prova ontológica serve assim a descrever a subjetividade fenomenológica como consciência pré-reflexiva, cuja "existência implica

\footnotetext{
6 Ibidem, loc. cit.
}

${ }^{7}$ SARTRE, J P. L'être et le néant: essai d'ontologie phénoménologique. Paris: Gallimard, 2001, p. 16. 
a essência" e cujo "ser é a fonte e a condição de toda possibilidade"». Quais são as consequências dessas teses? Supondo ao mesmo tempo o caráter de fato e originariamente ativo da consciência, Sartre reconhece sua natureza ontológica, delimitando assim a questão de suas possíveis determinantes. A fenomenologia sartriana começa, portanto, pela subjetividade que é "um todo pleno de existência, e esta determinação de si por si é uma característica essencial" ". Assim, a consciência começa a ganhar certos traços que nos fazem pensar a metafísica escolástica ou cartesiana com suas definições de Deus como o esse per se, ou aquela de causa sui ipsius. Sartre é plenamente consciente de suas referências teológicas afirmando em seguida que a consciência é um absoluto de existência que, como fenômeno, Descartes substancializou e exteriorizou chamando-a Deus. O autor de L' Etre et le néant consegue assim desteologizar a filosofia e ao mesmo tempo assumir a possibilidade de desenvolver as interpretações positivas das vias teológicas cartesianas que se tornam assim uma fonte de experiência ontológica de uma alteridade em relação à consciência intencional do ser. A etapa seguinte de reinterpretação da prova ontológica se passa como segue: seu fundamento é - como acabo de indicar - a consciência espontânea, que precede toda reflexão. Nesse nível primário, Sartre formula o princípio de intencionalidade por afirmar "que a consciência em sua natureza mais profunda é relação a um ser transcendente", e em seguida que "ser consciente de alguma coisa é estar diante de uma presença concreta e plena que não é a consciência" ${ }^{10}$. Nessa referência originária ao outro, constata-se que é justamente o outro que não é para apreender, pois, após a apreensão intencional, o que é apreendido não é senão o objeto cujo "ser é um puro não-ser" "11. Assim, o autor de $L$ ' être et le néant avança uma outra fórmula, que se refere à prova ontológica, a saber, que "a consciência nasce sustentada por um ser que não é ela"12. Essa situação se inspira na descrição cartesiana em que o sujeito é orientado

\footnotetext{
8 Ibidem, p. 21.

9 Ibidem, p. 22.

${ }^{10}$ Ibidem, p. 27.

${ }^{11}$ Ibidem, loc. cit.

${ }^{12}$ Ibidem, p. 28.
} 
para os entia, mas no ato de conhecer ele os transforma inevitavelmente em objeto. Assim, produz-se um intervalo irredutível entre a consciência e o ser, expresso em termos sartrianos como a oposição do ser-para-si e do ser-em-si. A consciência se constitui graças e por meio da experiência da alteridade do ser, e, por conseguinte, o seu caráter de ser absoluto torna-se completamente relativo: "a subjetividade absoluta não se pode constituir senão diante de um revelado, a imanência não se pode definir senão na apreensão de um transcendente"13.

O dispositivo que transforma a prova metafísica da existência de Deus em descrição ontológica da experiência intencional impede ou suprime a possibilidade da emergência da questão de Deus? A resposta é positiva até o momento da análise da propriedade essencial da subjetividade que é a liberdade. O problema da liberdade intervém no raciocínio de Sartre sobre a origem da negação. Ele se apóia e se inspira na empresa da dúvida cartesiana, interpretada como a capacidade "de se pôr fora do ser"14. Redução fenomenológica, a operação da dúvida é na verdade um ato "de se pôr fora de circuito em relação a um existente" que indica a possibilidade "de lhe escapar", de "se retirar" na imanência. A liberdade "que precede a essência do homem e a torna possível" é ainda uma figura da prova ontológica cuja descrição fenomenológica torna-se mais concreta. Os atos de "questionamento, a dúvida metódica, a dúvida cética, a époche" confirmam a possibilidade para a realidade humana do desprendimento do mundo, que para Sartre significa "desarraigamento dela mesma", o que quer dizer um modo de intencionalidade próprio à ação.

Combinando os temas evocados acima, Sartre descreve em seguida a facticidade do ser-para-si, referindo-se novamente às Meditações de Descartes, dessa vez na tentativa de obter a significação da prova da existência de Deus fundada sobre a constatação dos defeitos próprios ao ego que descobre sua finitude. $\mathrm{O}$ recurso à experiência originária, "desta apreensão do ser por ele mesmo como não sendo seu próprio fundamento, que está no fundo de todo cogito", explica as premissas da prova da existência de Deus, que, segundo Sartre, representa uma hipóstase da

\footnotetext{
${ }^{13}$ Ibidem, loc. cit.

${ }^{14}$ Ibidem, p. 59.
} 
síntese impossível do ser-para-si e do ser-em-si. Em outras palavras, da subjetividade e do ser em direção ao qual ela é dirigida. De fato, trata-se "de um descompasso entre o tipo de ser que ele pode conceber e o ser que ele é"15. Ele expõe, portanto, a situação e o caráter da subjetividade humana "como uma falta de ser diante do ser", ela é a compreensão de sua própria contingência, "um ser que não é seu próprio fundamento, que, enquanto ser, poderia ser outro que ele é". O caráter incompleto do cogito, que se refere àquilo que lhe falta, se exprime essencialmente em termos de ações e de valores. Nesse sentido, no cogito "assombrado pelo ser" surge o desejo, que é uma estrutura intencional que visa uma plenitude infinitamente distanciada "que por seu surgimento se supera em direção ao ser, qualificando-se em seu ser como ser a quem falta a coincidência consigo para ser aquilo que ele é"16. Sartre admite, nesse contexto, o mesmo rigor da prova cartesiana, no sentido de que "o ser que não é fundamento senão de seu nada, supera-se em direção ao ser que é fundamento de seu ser", mas acrescentando, entretanto, que "não é um Deus transcendente: ele se encontra no coração (da realidade humana), ele não é senão ela própria como totalidade" 17 .

Se o pensamento de Sartre podia ser qualificado como a filosofia que liga as descobertas de Husserl e de Heidegger, mantendo, entretanto, o primado do cogito em sua interpretação ontológica, parece que é seu apoio exclusivo na intencionalidade do tipo de objeto, mesmo deslocado numa dimensão existencial da ação, que abriu a possibilidade de a superar, ou melhor, de invertê-la - o que se faz no pensamento de Emmanuel Lévinas. Sigamos suas teses, segundo o método aqui adotado, de se deslocar inteiramente ao longo do eixo designado por caminho "cartesiano". Como se sabe muito bem, desde as primeiras páginas de Totalité e infini, Lévinas assume a ideia cartesiana do infinito, qualificando-a como experiência da alteridade absoluta. Lembremo-nos que essa problemática no próprio Descartes - ao menos segundo a interpretação tradicional não aparece senão na Terceira Meditação e que Husserl a considerava

\footnotetext{
${ }^{15}$ Ibidem, p. 115-116.

${ }^{16}$ Ibidem, p. 126.

${ }^{17}$ Ibidem, loc. cit.
} 
fenomenologicamente absurda. Como podemos, portanto, compreender esse "salto" no meio do raciocínio cartesiano, seria um gesto de colocar em questão o primado do cogito, uma espécie de reserva expressa em relação ao encadeamento da ordem meditativa cartesiana? É de modo diferente porque o objetivo declarado do autor de Totalité et infini é: "uma defesa da subjetividade como fundada na idéia do infinito"18. A razão pela qual Lévinas introduz desde o primeiro momento a ideia do infinito como a experiência paradigmática é fazer um desenvolvimento radical do método fenomenológico. Dessa vez, não estaria somente a pesquisar a possibilidade de efetuar "um passo atrás", supondo preliminarmente um primado teórico ou existencial da consciência voltada intencionalmente para o mundo em sua totalidade. Tratar-se-á antes de:

reconduzir a uma situação em que a totalidade se quebra, enquanto essa situação condiciona a própria totalidade. Tal situação é o esplendor da exterioridade ou da transcendência no rosto de outrem. $\mathrm{O}$ conceito dessa transcendência rigorosamente desenvolvida exprime-se pelo termo de infinito ${ }^{19}$.

Na situação inicial descrita por Lévinas, a separação da ordem da consciência e aquela da transcendência se encontra mantida ou mesmo radicalizada em relação a Sartre, o que faz a ligação das duas ordens a torna ao mesmo tempo fenomenologicamente concreta como o fenômeno do rosto. O que é, entretanto, decisivo é que Lévinas faz uma inversão completa do processo de intencionalidade, no qual já não é o pensamento que se dirige para o mundo, mas é o infinito que precede e assim constitui o pensamento. À hesitação ou indecisão de Sartre, no que concerne ao caráter absoluto da subjetividade e à possibilidade de tratá-la como ponto de partida, Lévinas apresenta a descrição de um evento, ou de uma revelação da ideia de infinito, cuja manifestação constituinte decide por seu primado:

O infinito não é a princípio para se revelar em seguida. Sua infinição

\footnotetext{
${ }^{18}$ LÉVINAS, Emmanuel. Totalité et infini. Paris: LGF,1971, p. 11.

${ }^{19}$ Ibidem, p. 9-10.
} 
produz-se como revelação, como infusão de sua idéia em mim. Ele se produz no fato inverossímil em que um ser separado fixado na sua identidade (...) contem no entanto em si - o que não pode nem conter, nem receber somente em virtude de sua identidade ${ }^{20}$.

Retomemos o fio cartesiano de nossa pesquisa. É necessário dizer, em resposta à objeção possível referente à introdução da ideia do infinito, que Lévinas, levando em conta o caminho cartesiano desde seu início, começa pelo momento privilegiado, pela virada à luz da qual as diferentes etapas desse caminho podem ser, enfim, bem compreendidas. Comecemos então, conforme o exemplo das Méditations, pela situação da dúvida que, segundo Lévinas: "não é somente uma aventura pessoal vivida por Descartes" ${ }^{21}$. Para o fenomenólogo, é uma situação originária da aparição do mundo que se caracteriza por uma certa ambiguidade ou pela incerteza quanto à veracidade da experiência, a princípio, sensível; em seguida, estende-se também ao conhecimento das matemáticas. $\mathrm{O}$ problema da ambiguidade reside no fato de que: "o que aparece não se degrada de forma nenhuma no nada" ${ }^{22}$, mas, por sua vez, está longe de ser. Assim, a dúvida que se instala:

diz respeito à sinceridade do que aparece, como se nessa aparição silenciosa e indecisa se contasse uma mentira, como se o perigo do erro proviesse de um engano (...). O mundo silencioso é o mundo que nos vem de outrem, ainda que fosse de um gênio maligno. ${ }^{23}$

Assim, o fenomenólogo da transcendência mostra que o passo autônomo que se dirige para a emergência da subjetividade, de fato, implica já uma certa experiência da alteridade. Donde "o cogito não fornece começo a esta interação do sonho. Há no cogito cartesiano, certeza primeira (mas que, para Descartes, repousa já sobre a existência de Deus),

\footnotetext{
${ }^{20}$ Ibidem, p. 12

${ }^{21}$ Ibidem, p. 90.

${ }^{22}$ Ibidem, p. 91.

${ }^{23}$ Ibidem, loc. cit.
} 
uma parada arbitrária, que não se justifica por ela mesma"24. Lévinas, no entanto, passa a um nível de interpretação mais profunda e afirma que o ato da dúvida não faz certamente de modo algum parte integrante do raciocínio que conduz ao cogito, porque esse "descobrimento" já está presente em sua premissa e, de fato, é um ato de "romper com a participação" e, por isso, de estabelecimento da separação definitiva. A dúvida conduz ao cogito autônomo ou "ateu" e, em seu momento da negação, uma referência à alteridade será sempre incluída.

$\mathrm{Na}$ negatividade que se manifesta pela dúvida (...) não sou eu - é o Outro que pode dizer sim (...). Ele está no começo da experiência. Descartes procura uma certeza e se depara na primeira mudança de nível com essa descida vertiginosa. (...) é, porque de fato possui a idéia do infinito, que pode medir de antemão o retorno da afirmação atrás da negação ${ }^{25}$.

Relativizando a importância da dúvida como condição necessária para atingir a evidência do cogito, Lévinas igualmente põe em questão o sentido fundamental do cogito compreendido como um modelo de evidência supratemporal, na medida em que, segundo o autor de Totalité et infini, seu descobrimento é já engajado num processo temporal no qual "o começo do cogito lhe resta anterior" ${ }^{26}$. Entretanto, seu sentido próprio consiste em:

o despertar de uma existência que apreende sua própria condição. (...) Antes do cogito, a existência sonha com ela mesma, como se ela permanecesse estranha a si. É, porque suspeita que sonha consigo, que ela desperta (...) mas essa suspeição, essa consciência da dúvida, supõe a idéia do Perfeito ${ }^{27}$.

\footnotetext{
${ }^{24}$ Ibidem, p. 93.

${ }^{25}$ Ibidem, p. 94.

${ }^{26}$ Ibidem, p. 85.

${ }^{27}$ Ibidem, loc. cit.
} 
Lévinas reconhece então a maneira particular da aparição da ideia do infinito pela atividade subjetiva, que somente em seu ato descobre seu condicionamento. $\mathrm{O}$ autor de Totalité et infini admite, então, o duplo movimento da metafísica cartesiana:

se, numa primeira démarche, Descartes toma consciência indubitável de si por si, numa segunda démarche - reflexão sobre a reflexão percebe condições dessa certeza. Essa certeza mantém a clareza e a distinção do cogito - mas a própria certeza é procurada por causa da presença do infinito nesse pensamento ${ }^{28}$.

Descartes, afirmando então que "De alguma maneira tenho primeiramente em mim a noção do infinito que do finito, quer dizer de Deus que de mim mesmo"29, estabelece a distinção radical entre as ideias objetivas que provêm da atividade cognitiva própria, baseada sobre a compreensão de seu conteúdo, e a única "ideia" que não pode ser constituída. O esquema da prova ontológica, tão importante para Sartre, para Lévinas é um gesto de acolhimento da ideia independente e autônoma em relação à consciência que a pensa. Lévinas observa, todavia, que a ideia cartesiana de Deus em seu excedente conserva traços de racionalidade, que não se dissolvem nas emoções próprias à consciência religiosa. $\mathrm{O}$ sentido da separação das duas ordens consiste em que a ideia do infinito, permanecendo exterior admite uma espécie de autonomia em relação ao cogito, que desde então se caracteriza por "uma receptividade sem passividade, uma relação entre as liberdades" ${ }^{30}$. Embora Descartes não tenha reconhecido o sentido ético da ideia do infinito, que se concretiza fenomenologicamente no rosto de outrem, mantendo-se no campo da Teoria do conhecimento, chega ele a mostrar, entretanto, a modificação da subjetividade resultante da posse da ideia do infinito. Assim, o cogito suspende sua atividade de objetivação

\footnotetext{
${ }^{28}$ Ibidem, p. 232.

${ }^{29}$ AT IX, 36 (A referência usada para os textos de Descartes é a edição Adam et Tannery (Oeuvres de Descartes, publiées par Charles Adam et Paul Tannery, 11 volumes, Paris, Vrin, 1996). Na notação simplificada usada internacionalmente, AT indica a edição; os numerais romanos, o volume; e os algarismos arábicos, o número da página).
}

${ }^{30}$ Totalité et infini, p. 233. 
e uma relação pessoal nasce, em que o ego repleto de admiração, de adoração e de alegria vive "uma contemplação da majestade divina, que nos faz desfrutar do maior contentamento" 31 . Essa modificação do cogito pela ideia do infinito se traduz de maneira significativa não na teoria, mas na ação, relembrando a estrutura do desejo, já evocada por Sartre. Mas o desejo não se resume em intencionalidade do ego, que toma consciência de seus defeitos, mas inversamente:

O movimento parte do pensado e não do pensador (...). O infinito não é objeto de um conhecimento - o que o reduziria à medida do olhar que contempla - mas o desejável, o que suscita o Desejo, quer dizer, o que é acessível por um pensamento que a todo instante pensa mais do que ele pensa. (...) O desejo é uma aspiração que o Desejável anima; nasce a partir do seu "objeto", é revelação ${ }^{32}$.

A Fenomenologia da doação de Jean-Luc Marion pode ser tratada como uma tentativa de síntese das conquistas da Fenomenologia, ao mesmo tempo no que diz respeito a suas intenções iniciais (Husserl) e a seu desenvolvimento na fenomenologia não objetiva (Heidegger, Lévinas, Henry). Uma certa dificuldade se põe, entretanto, quando se trata de aplicá-la à filosofia cartesiana do infinito, segundo o fio condutor de nossa pesquisa. Ora, poderia parecer que um tal quadro de análise deveria mostrar-se particularmente bem sucedido no caso de um dos maiores intérpretes contemporâneos da filosofia de Descartes. Todavia, pode-se ter a impressão que na obra fenomenológica do filósofo francês, apesar de suas competências excepcionais nessa matéria, a referência cartesiana costuma aparecer sem oferecer imagem clara da "via cartesiana". Uma leitura mais cuidadosa permite, entretanto, determinar a posição de Marion sobre essa questão, o que iremos tentar fazer.

No Étant Donné, o autor tenta inicialmente validar fenomenologicamente a noção central da doação. Nessa noção, podese notar o acento cartesiano-husserliano posto sobre a universalidade da

\footnotetext{
${ }^{31}$ Méditations, AT IX, 42.

${ }^{32}$ Totalité et infini, p. 56.
} 
experiência fenomenológica, condicionada pela atitude receptora do sujeito (a redução) que decide pela possibilidade da doação do fenômeno em questão. $\mathrm{O}$ autor tenta ampliar o domínio fenomenológico constituído pela primeira fenomenologia objetiva ou ontológica, por demonstrar a natureza doadora dos fenômenos do "nada". Nesse contexto, Marion fornece a lista de exemplos de tais fenômenos descritos na História da Filosofia, criando assim um espaço de univocidade fenomenológica marcada pelo caráter não objetivo da fenomenalização. Por sua vez, são listados: o fenômeno do nada descrito por Heidegger, o fenômeno da possibilidade como alguma coisa não contraditória (Leibniz), o fenômeno da intenção vazia de Husserl, o desejo sartriano; enfim, são evocados três exemplos segundo um tipo particular de fenomenalidade da "não obscuridade de aparecer", a saber, a ideia kantiana da razão, a Dialética hegeliana do negativo, assim como "o incompreensível que dá o excesso positivo do infinito, segundo suas exigências próprias de manifestação (Denys, Descartes)" "33. Vemos então que, por um lado, a ideia do infinito é considerada como o fenômeno que se dá de uma maneira não objetiva, no entanto, por outro lado, por comparação com sua função desempenhada no pensamento de Lévinas, é preciso confessar que ela perde claramente seu estatuto privilegiado.

Certa relativização da noção cartesiana que não se torna senão um protótipo de estrutura fenomenológica universal é, em seguida, aprofundada na análise dos casos de exceções ao princípio de razão suficiente ou de princípio de causalidade que aparecem no pensamento metafísico. Nesse contexto, dois exemplos coincidem: aquele de um acidente ou de um incidente que já não pode ser introduzido no sistema da causalidade, e aquele de Deus que aparece como:

incausabilidade por excesso, essência infinita, que se excetua de toda relação unívoca com seus efeitos sempre finitos, a fortiori, com o menor antecedente, irrepetibilidade do único, indisponibilidade do imprevisível, porque invisível, incompreensibilidade por suplemento, mesmo de qualificações, então de evidência ${ }^{34}$.

${ }^{33}$ MARION, J-L. Étant donné:essai d'une phenomenology de la donation, Paris: PUF, 2005, p. 81.

${ }^{34}$ Ibidem, p. 226. 
A doutrina metafísica de Deus como ens a se serviria de modelo para todo fenômeno que se dá analogicamente como em Sartre, em que ela foi utilizada para descrever a referência da consciência irrefletida? Marion estando bem consciente do problema põe a questão: "Querer-se-ia reivindicar para o si daquilo que mostra o si do a se positivo, identificar o fenômeno dado ao "Deus" da "Metafísica"35? Ele responde imediatamente: "Essa empresa não teria, evidentemente, nenhum sentido", acrescentando logo após: "não se pode rejeitar - uma recusa ela também sem razão - a surpreendente isomorfia do Deus incausável e do fenômeno sem razão: ao menos, formalmente, um e outro se beneficiam do mesmo e extraordinário privilégio" 36 .

Na elaboração da fenomenologia da doação, Marion introduz uma classe de fenômeno de tipo particular, que se caracteriza pelo fato de que por definição o intelecto não é capaz de apreendê-lo, porque, no processo de sua fenomenalização, ele advém excedendo e "saturando" as categorias kantianas da quantidade, da qualidade, da relação e da modalidade. O fenômeno saturado aparece então como invisável, insuportável, absoluto, inobservável. Nessa perspectiva fenomenológica radical, Marion retoma o exemplo da ideia cartesiana do infinito, que, exceção em relação a todas as ideias objetivas, preenche as "condições" do fenômeno saturado. Ela não se submete aos termos quantitativos, ela se impõe a um olhar ofuscado tota simul; segundo a qualidade, é um maximum positivo (maxime clara et distincta, vera maxime); segundo a relação, ela não permite sua construção por analogia com uma outra ideia qualquer (ela não autoriza senão uma "aproximação" ou um "tocar" do espírito); em termos de modalidade, no lugar de ser constituída pelo Eu como um objeto, "ela o compreende sem se deixar compreender por ele, de modo que mesmo o ego poderia talvez também ser interpretado por vezes como um interpelado"37. A questão que se põe é: Até onde se estende esse privilégio, sem dúvida, profundamente levinasiano, concedido à ideia de infinito? A univocidade fenomenológica é posta em causa no conceito de saturação? Em nenhum

\footnotetext{
${ }^{35}$ Ibidem, loc. cit.

${ }^{36}$ Ibidem, loc.cit.

${ }^{37}$ Ibidem, p. 306.
} 
caso, como testemunha, o fato de que Marion, em seguida, verifica que o sublime kantiano e o conceito do tempo íntimo husserliano lhe são, de certo modo, comparáveis e têm o mesmo direito à noção de saturação. Melhor, a propósito do último dos fenômenos mencionados aqui, o filósofo sublinha sua vantagem em relação aos precedentes, em virtude de sua universalidade de aplicação.

Adémarche das Méditations, que chamamos aqui a "via cartesiana", revela-se finalmente mais útil para determinação da subjetividade que, segundo Marion, se recebe do que ela recebe, sendo essencialmente constituída pela resposta ao chamado que a precede. Marion começa então sua leitura cartesiana pela situação da dúvida, da qual aparece "algum Deus ou alguma potência”, a propósito do qual o autor de Étant Donné nota que não tem nem existência nem essência, permanecendo na indeterminação quase total. O que é importante nisso é essa alteridade originária com a qual a subjetividade entra em debate interior sobre sua origem. $\mathrm{Na}$ atitude da dúvida, examinando a possibilidade de sua inexistência, ou de ser enganado, o sujeito se persuade dele mesmo - "não há portanto dúvida de modo algum que eu sou se ele me engana" 38 - assim não se cria espontaneamente, como queria Sartre, mas se recebe como tributário, é tal subjetividade que a princípio não se pensa ela mesma, mas é "originariamente pensada por um outro pensamento, que me pensa sempre já, mesmo se eu não posso ainda, nem identificar a essência, nem demonstrar a existência" ${ }^{39}$. Antes que o sujeito seja capaz de se determinar como uma coisa que pensa, ele é já coisa pensada. "O ego cogitado, tanto quanto cogitante, acede a sua primeira existência a partir de um chamado que disso o persuade, ego persuasus" ${ }^{40}$. Que oferece então o momento seguinte da via cartesiana em que a ideia positiva de Deus é introduzida (na III Meditação)? Deus que em sua ideia se manifesta, segundo Descartes, como "todo-poderoso, infinito e incompreensível", faz que o sujeito, originariamente assim interpelado, estabeleça sua relação com a alteridade "já não sobre o modo do conflito,

\footnotetext{
${ }^{38}$ AT IX, p. 19.

${ }^{39}$ Ibidem, p. 378.

${ }^{40}$ Ibidem, p. 379.
} 
mas sobre aquele da imagem e semelhança"41. Desse modo, nessa nova situação, a subjetividade em sua atividade de pensamento torna-se consciente de sua posição no espaço transcendental infinito. $\mathrm{O}$ modo de semelhança significa então um acontecimento único que consiste no fato de que o pensamento de si mesmo por si mesmo é igualmente pensado da ideia de Deus, respeitando, entretanto, a precedência do infinito sobre o finito. No modo da imagem, o sujeito finito deseja intencionalmente o infinito, sabendo que "aquele do qual dependo possui em si todas essas grandes coisas às quais aspiro" ${ }^{42}$. Desse modo, a presença imanente da ideia de infinito no modo da semelhança:

põe em plena luz o modelo originário do chamado e da resposta o chamado se atesta no primeiro pensante, o interlocutor infinito, a resposta se realiza com o finito, primeiro existente, certamente pensante, mas, sobretudo primeiramente pensado porque imediatamente interpelado. $^{43}$

Acabamos de analisar quatro exemplos do pensamento fenomenológico do infinito seguindo seu momento cartesiano no contexto do debate recente sobre a "virada teológica". Podemos concluir que o fio cartesiano permitiu obter alguns elementos cruciais desta análise. Ora, qualquer que seja a versão da fenomenologia em questão, seja epistemológica, seja existencial, seja ética, seja da doação, encontra-se uma referência permanente ao fenômeno do infinito e, por conseguinte, ao lugar a partir do qual se põe a questão de Deus. Entretanto, parece verdadeiramente decisivo a inversão do sentido da intencionalidade fenomenológica que, ao invés de partir do sujeito, originariamente advém a ele, assim o constituindo. A atividade subjetiva segundo o modelo da contraintencionalidade se determina previamente por uma instância do chamado, da interpelação e da interlocução. A tendência aberta por Lévinas, que exprime uma possibilidade da descrição dos fenômenos que vão além

\footnotetext{
${ }^{41}$ Ibidem, p. 382.

${ }^{42}$ AT VII, 51.

${ }^{43}$ Etant donné, p. 383
} 
da objetividade, sem dúvida encontra sua continuação na fenomenologia da doação. Contudo, como pudemos constatar, o projeto fenomenológico de Marion - ao menos no início - tenta validar uma estrutura fenomenológica universal, que é a da doação, e não, como é o caso de Lévinas, identificar um fenômeno-chave (da epifania do rosto) que, em seguida, decide pelo primado da Ética em relação a qualquer outro conteúdo fenomenológico.

Para Marion é o inverso, percebemos uma certa reserva em relação à atitude ética que leva finalmente ao privilégio não justificado de um fenômeno que na sua indeterminação essencial não fornece nenhuma solução para um dos maiores desafios da fenomenologia, que é a questão da individuação do outro. Se, como o vimos, há um acordo entre Lévinas e Marion no que concerne às duas etapas do "caminho cartesiano" da interiorização da ideia do infinito, o primeiro o explora imediatamente sobre o plano ético, enquanto que o segundo o aplica a diferentes tipos de fenômenos saturados (dos quais um é precisamente aquele do ícone ou do rosto). A ideia do infinito não é nesse caso senão um anúncio longínquo e modesto do fenômeno da revelação em que atuam todos os quatro tipos de saturação fenomenológica no seu próprio excesso. Assim, ela não pressente senão vagamente a questão intersubjetiva radical que se situa "para além do bem e do mal", que é aquela do amor.

Concluo com uma observação acerca do estatuto da ideia do infinito na fenomenologia de Marion. Podemos espantar-nos por uma relativização dessa ideia, que no discurso marioniano se reduz somente a desempenhar um papel de abertura do espaço da doação ou eventualmente representar um protótipo metafísico do fenômeno saturado. Duas razões parecem explicar bem este estado de coisas. Primeiramente, retomando a fórmula metodológica de Marion, que diz que "tanto de redução, tanto de doação" é necessário dar-se conta de que a redução marioniana já não é uma simples "colocação entre parêntese" de um transcendente, mas, na verdade, consiste frequentemente numa desconstrução dos conceitos fundamentais próprios à Metafísica. Nesse sentido, apesar de suas vantagens fenomenológicas, o "Deus" cartesiano que entra na Filosofia sob a figura do infinito deve ser igualmente reduzido e, após sua redução, pode ser justaposto com qualquer fenômeno dado ou saturado. Assim, Descartes, sob a figura do infinito, não oferece senão uma estrutura que pode ser aplicada e desenvolvida 
em Fenomenologia, sem trazer, contudo, nada de excepcional à questão fenomenológica de Deus. Em segundo lugar, a ideia cartesiana do infinito não se torna uma figura teológica maior, pois ela se esboça de maneira muito mais radical no fenômeno da revelação do Cristo, que satura por seu excesso os quatro tipos do fenômeno saturado. Assim, o fenômeno de revelação não aparece somente como ícone (rosto de outrem), mas também intervém na história como evento histórico, em seguida, suscita admiração como ídolo e, enfim, afeta, penetrando-o e constituindo, o corpo próprio.

Data de registro: $16 / 10 / 2011$

Data de aceite: 16/11/2011 